\title{
Bridging the gap between climate scientists and decision makers
}

\author{
D. J. Griggs*, T. S. Kestin \\ Monash Sustainability Institute, Monash University, Victoria 3800, Australia
}

\begin{abstract}
Despite the increasing scientific evidence that human-induced climate change poses a major risk to human and natural systems, there appears to be a decline in the momentum for action to reduce this risk, and more alarmingly a decline in the trust the public holds in the scientific evidence itself. In this paper we explore the role and responsibilities of the climate science community in overcoming this gap in perceptions, and also describe some initiatives underway in Australia that help the climate science community to proactively engage with policymakers and business leaders.
\end{abstract}

KEY WORDS: Climate change $\cdot$ Climate science community $\cdot$ Communication $\cdot$ Decision making Climate Works · Australia

\section{INTRODUCTION}

Despite increasing scientific evidence for the link between human activities and observed and projected climate change, there are indications that public acceptance of these scientific results is declining. This growing perception gap, and the spate of recent criticisms of both the science and individual scientists, has led to increasing frustration within the climate change science community (hereafter 'science community') about what can be done to better convey the science.

This paper describes several initiatives we have worked on with the purpose of connecting climate scientists with policymakers, business leaders, the media and the wider public over the issue of climate change.

However, before we describe these initiatives in Section 4 , we set the context by briefly reviewing the recent state of public understanding of climate change (Section 2) and its implications for the role of the science community in communicating climate change (Section 3). In particular, there has been a considerable amount of research showing that closing the gap is not just a matter of providing more or better scientific information, as public attitudes to climate change are shaped by a wide variety of non-scientific (and some- times non-rational) factors. This research is helpful in both defining the most effective roles for climate scientists in engaging with the public, and in allowing the science community to appreciate just how far it has already come.

\section{PERCEPTION GAP}

In this section we briefly review the perception gap between the scientific consensus on climate change and public understanding of the science, and suggest some of the reasons for this gap.

\subsection{Scientific consensus}

There is overwhelming scientific evidence in support of an observable human-induced influence on climate that is likely to pose significant risks to human and natural systems unless action is taken to reduce emissions of greenhouse gases.

The Intergovernmental Panel on Climate Change (IPCC) Fourth Assessment Report Working Group I (Solomon et al. 2007), an assessment by over 750 
authors of over 5000 scientific publications on climate change to date, concluded that, based on many independent sources of evidence,

Warming of the climate system is unequivocal, as is now evident from observations of increases in global average air and ocean temperatures, widespread melting of snow and ice, and rising global average sea level (p. 5) and

Most of the observed increase in global average temperatures since the mid-20th century is very likely due to the observed increase in anthropogenic greenhouse gas concentrations. (p. 10)

Both statements reflect a very high degree of confidence in the connection between anthropogenic greenhouse gases and observed climate change. The IPCC used the following terms to describe the confidence levels in its statements:

The following terms have been used to indicate the assessed likelihood, using expert judgment, of an outcome or a result: Virtually certain $>99 \%$ probability of occurrence, Extremely likely $>95 \%$, Very likely $>90 \%$, Likely $>66 \%$, More likely than not $>50 \%$, Unlikely $<33 \%$, Very unlikely $<10 \%$, Extremely unlikely $<5 \%$. (p. 3)

The first statement above is considered to be unequivocal, i.e there is no doubt. If, in the opinion of the IPCC Fourth Assessment Report's authors, there had been even a $<1 \%$ chance that this statement was not correct, then the term virtually certain would have been used. The second statement is deemed to be 'very likely', so there is a $>90 \%$ chance that this statement is correct.

There are very many similar statements in the IPCC Fourth Assessment Report which reinforce the very high level of confidence of the authors in support of a humaninduced influence on climate. Recent climate science studies have supported and strengthened these conclusions (e.g. Allison et al. 2009, Richardson et al. 2009).

Solomon et al. (2007) also provides projections of potential future global temperature changes (Fig. 1), which underline the significant magnitude of risks posed by climate change if greenhouse gas emissions are not reduced.

\subsection{Public perceptions of climate change}

Despite the overwhelming scientific evidence for human-induced climate change, public acceptance of the evidence has been far from unanimous and, more alarmingly, has declined recently. For example, a BBC poll in the UK found that the number of people who think climate change is taking place declined from

1BBC (2010) Climate scepticism 'on the rise', BBC poll shows. BBC News. news.bbc.co.uk/2/hi/8500443.stm. Accessed 28 April 2010
$83 \%$ in November 2009 to $75 \%$ in February 2010프. An Infratest poll for Der Spiegel found that the number of Germans worried about climate change dropped from $62 \%$ in 2006 to $42 \%$ in March 2010². In the USA, a Gallup poll found that the percentage of Americans believing climate change has already begun or will be visible within a few years dropped from a high of $65 \%$ in 2008 to $53 \%$ in $2010^{3}$.

A combination of recent events points to an explanation for the recent decline in the public trust in climate change science:

- The theft and publication of emails from the University of East Anglia purporting to show that climate scientists manipulated data.

- The discovery of 2 minor errors in the IPCC Fourth Assessment Report of Working Group II (Parry et al. 2007) which led to wide-ranging attacks on the IPCC process and leadership.

- The relatively cold and snowy winter of 2010 in Europe and the eastern United States, which was used to bolster arguments that the world has not warmed since 1998.

- The failure of world governments to reach a binding international agreement on post-Kyoto Protocol greenhouse gas emission reductions at the United Nations Framework Convention on Climate Change Conference of the Parties in Copenhagen in December 2010. In Australia this was one of the contributing factors for the government's failure to institute a national emissions trading scheme.

While there is some evidence that public trust in climate change was falling for some time (e.g. Pew 2009), these recent events were seized on by the media and blogosphere, singly and in combination, as proof that the entire science of climate change should be discredited. Although these criticisms have done nothing to materially undermine the scientific evidence of climate change, their cumulative effect clearly reduced the public's confidence in it.

\subsection{Public perceptions of climate change in context}

Taking a longer term and wider perspective, however, it is perhaps not surprising that public trust in climate change science is incomplete and varies over time. In fact, it could be said that the science commu-

\footnotetext{
2The Local (2010) Germans lose fear of climate change after long, hard winter. www.thelocal.de/sci-tech/20100327-26163. html Accessed 28 April 2010

${ }^{3}$ Newport F (2010) Americans' global warming concerns continue to drop. www.gallup.com/poll/126560/americans-globalwarming-concerns-continue-drop.aspx. Accessed 28 April 2010
} 


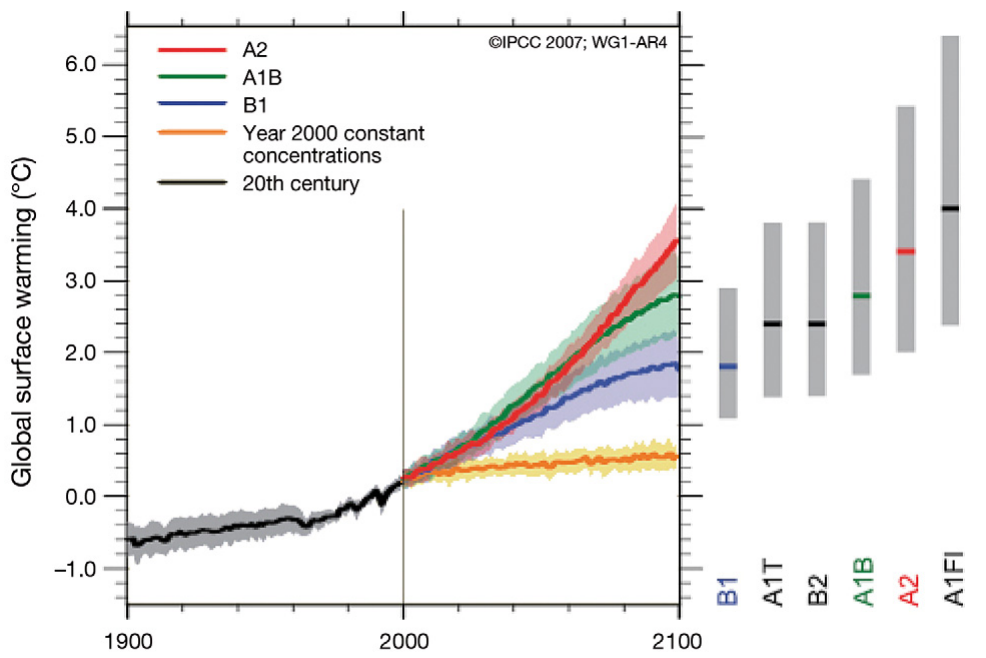

Fig. 1. Multi-model global averages of surface warming (relative to 1980-1999) (solid lines) for the scenarios A2, A1B and B1, shown as continuations of the twentieth century simulations. Shading denotes the \pm 1 standard deviation range of individual model annual averages. Orange line: experiment where concentrations were held constant at year 2000 values. Grey bars at right: best estimate (solid line within each bar) and likely range assessed for the 6 SRES marker scenarios. Assessment of the best estimate and likely ranges in the grey bars includes the AOGCMs in the left part of the figure, as well as results from a hierarchy of independent models and observational constraints.

(Source: Fig. SPM.5 from Solomon et al. 2007) nity, together with a wide variety of other stakeholders, has done an outstanding job of increasing awareness of climate change as an issue of importance.

Climate change is perhaps the most complex issue that science has brought to the attention of society. The complexity of the underpinning science is beyond the grasp of most non-specialists, making the many uncertainties in our understanding of the science and the projections of future climate change even harder to explain. Its effects are outside the public's direct experience: greenhouse gases are invisible, their causal effects on climate are intangible, and little of the effect of climate change has been felt to date as a majority of the impacts will occur in the future. The causes of climate change are so intertwined with the modern way of life that addressing them requires dealing with many social, political and economic norms and interests. Climate change is just one of the many environmental and other issues facing decision makers, many of them apparently more urgent to them than climate change. Finally, the public by no means automatically trusts science and scientists.

Given these barriers, the current degree of public awareness on climate change and the amount of major action that has taken place from international to local levels could be considered remarkable. For example, most countries have recognized climate change and have agreed to limit 'dangerous' climate change. The United Nations Secretary-General Ban Ki-moon 'has made addressing climate change a cornerstone of his tenure' (UN 2010), and almost all developed countries have committed to reduce greenhouse gas emissions under the Kyoto Protocol. Climate change has moved to become a generally accepted issue, featuring in everything from novels and movies to terrorist threats. A demonstration of just how much the issue has penetrated our society can be seen in Fig. 2.
Given the strong scientific consensus about the significant risks posed by climate change, however, there is considerable concern within the science community about the current decline in public trust of climate science-and specifically what the science community can do to restore and strengthen public acceptance of the scientific results.

\section{BRIDGING THE GAP}

In this section we discuss the general role of the science community in demonstrating that climate change is real and in providing information to assist decision makers plan appropriate actions.

Science is just one of the dimensions of the climate change issue. In order to convey the science more effectively, it is important for the science community to appreciate-and actively work with — the social, environmental, political, psychological, economic and cultural dimensions of climate change. There is often a sense in the science community that if more information or better explanations of climate change are provided, this will lead people to act. However, because of the additional dimensions of the issue, this rarely happens.

There is an extensive and growing body of literature examining how science, and in particular the science of climate change, can interact and build on these additional dimensions. It includes the roles of scientists in providing information (e.g. Pielke 2010, Oreskes et al. 2008, Oreskes 2004), the psychology of climate change communication (e.g. CRED 2009), the role of the media in communication (e.g. Boykoff 2009), and 'boundary management' - the integration of scientific information into decision making-(e.g. Cash et. al 2003). 


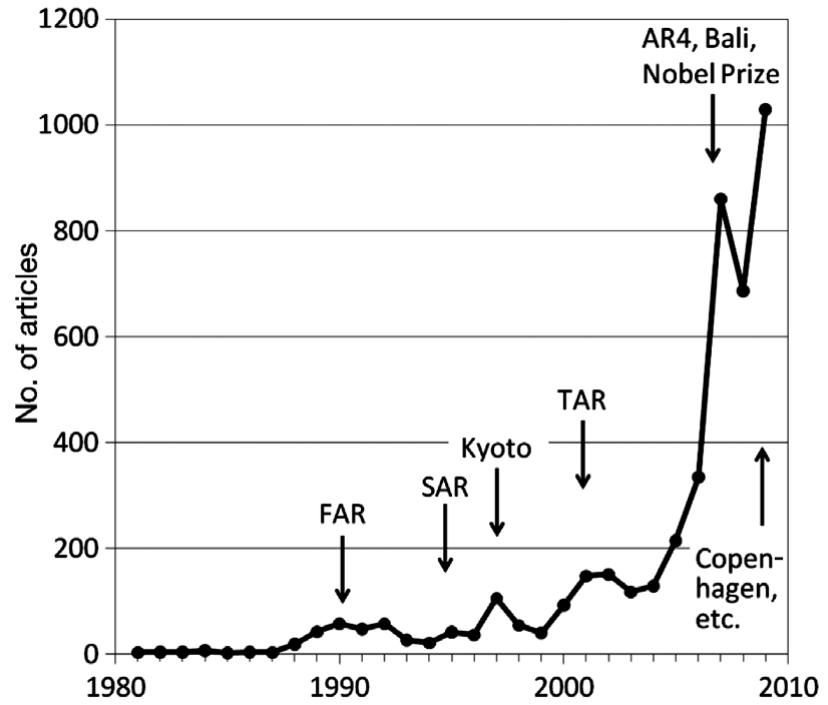

Fig. 2. Number of articles per year in the New York Times containing the phrase 'climate change', together with important climate change milestones: FAR (IPCC First Assessment Report), SAR (IPCC Second Assessment Report), Kyoto (UNFCCC COP 3 in Kyoto), TAR (IPCC Third Assessment Report), AR4 (IPCC Fourth Assessment Report), Bali (UNFCCC COP 13 in Bali), Nobel Prize (IPCC win of Nobel Peace Prize), Copenhagen (UNFCCC COP 15 in Copenhagen). The articles were found by entering 'climate change' into the New York Times' advanced online search facility, http://query.nytimes. $\mathrm{com} / \mathrm{search} /$ alternate/query?query=\&st=fromcse

It is beyond the scope of this paper to review this body of literature. However, one point made by Oreskes (2004) perhaps relates to the most basic role of the climate science community. The community is currently mostly focused on trying to provide the definitive 'proof' of climate change that 'deniers' and many decision makers demand before any action should be taken. Oreskes (2004) points out that it is unlikely such a proof exists, let alone that it will be found in the near future. However, the community does have a strong consensus, reflected through the IPCC assessments, about the reality and risks of climate change. In the history of science, and Earth sciences in particular, such a consensus has been sufficient for the science to continue advancing, and therefore for policy related to the science to advance as well. The climate change science community therefore has a role in actively conveying this strong consensus (where it exists) to the public and decision makers.

Of course not all climate change scientists should be - or need to be-interested in actively working with decision makers and the public; after all, scientists' primary role is to 'do' science. However, the scientific community as a whole has so far been less than effective in this channel of communication, in particular in conveying the community's consensus on climate change, as discussed in the previous paragraph.
This was clearly demonstrated in the recent attacks on climate change science, where much of the burden of defending the scientific results fell to individual scientists. National and international institutions of the community, both governmental and professional associations, were relatively silent. These institutions, which represent 'science' to policy makers and the public, have the access and resources to convey this consensus more strongly.

Internationally, institutions such as the World Meteorological Organisation (WMO), the World Climate Research Programme (WCRP) and the International Geosphere-Biosphere Programme (IGBP) are making substantial and increasing efforts to provide 'climate services'. For example, the WMO's World Climate Applications and Services Programme (WCASP) and its implementation arm, Climate Information and Prediction Services (CLIPS), aim to foster the effective application of climate knowledge and information for the benefit of society. To date these efforts have largely targeted specific users of climate information such as farmers and hydrologists rather than focusing on delivering the broader science message to policymakers, business leaders, and the public. There is a clear requirement for these organizations to focus on these critical stakeholder groups and to develop information and programmes tailored to meet their needs.

\section{EXAMPLES OF ENGAGEMENT: CLIMATEWORKS AUSTRALIA}

In this section we describe several initiatives that we have helped set up that try to help bridge the gap between climate science on the one hand and policymakers, business leaders, the media and the public on the other. These initiatives are among a growing number of grass-roots attempts by individual climate scientists to make climate change science and scientists more accessible to these audiences. They add to and complement actions by government institutions.

These initiatives - Climate Scientists Australia, Sustainable Futures Forums and Science Meets the Boardroom-are part of the activities of ClimateWorks Australia, a new partnership between Monash University and the Myer Foundation (a well known Australian philanthropic foundation), and use different modes of engagement to reach the different audiences.

\subsection{Climate Scientists Australia}

Climate Scientists Australia is an independent group of 13 senior climate scientists who hope to improve decisions on climate-related issues in Australia by 
encouraging better use of the science. It was set up after members of the group were frustrated with how scientific information about climate change and its impacts was often ignored, confused or misinterpreted by policymakers and the public in general.

As senior climate scientists they consider it their responsibility to provide impartial and authoritative information. They aim to present a balanced and comprehensive view on climate-related issues, counter misrepresentations of climate science, and bring new scientific findings to the attention of policymakers, business leaders, the media and the public.

All outputs from the group are based on science or the policy implications clearly deducible from the science. The group is not affiliated with or represented by any other organisation, and they do not directly advocate for any specific policies.

ClimateWorks Australia (see Section 4) hosts the Climate Scientists Australia Secretariat. This central coordination hub allows the group to operate effectively, and assists in the dissemination of the group's work. It includes development and maintenance of a website, secretarial support, and coordination of group meetings, events and publications. ClimateWorks Australia neither speaks on behalf of the group nor has any editorial control over information produced by the group.

One of the most effective activities of Climate Scientists Australia has been Parliamentary Briefing days, which the group undertook in October 2009 and March 2010, and plans to continue undertaking twice a year. The group spent the day in the Parliament House of Australia and offered confidential one-toone briefings with Members of Parliament (MPs) and Senators. This was followed by a closed lunchtime briefing and question-and-answer session, also for MPs and Senators, at which they could raise any issues of climate science. These events were cohosted by an MP or Senator from the Labor, Liberal and Greens parties so that they are seen to be nonpartisan. The feedback on the Parliamentary Briefing days held so far has been excellent, with 40 to $50 \mathrm{MPs}$ and Senators participating in these activities. It has also helped to develop relationships between the scientists and the parliamentarians who, on numerous occasions, have followed up with individual scientists 'out-of-session' for further information.

\subsection{Sustainable Futures Forums}

A changing climate presents new challenges for government, business and society as they manoeuvre towards a sustainable future. The issues are complex and require deep analysis and debate across a wide range of stakeholders. However, because of the intense public and media scrutiny, it is often difficult for real and open dialogue to take place in an objective fashion. As a result, genuine discussion on important issues is stifled, and decisions are delayed or made without the necessary analysis having taken place.

What ClimateWorks Australia felt was needed is a mechanism through which policymakers, business leaders and other key stakeholders can come together in a neutral environment where they are able to discuss the challenges of creating a sustainable future. The mechanism also needs to provide a means by which the practical solutions that emerge from these discussions can be carried out.

ClimateWorks Australia in partnership with the Cranlana Programme, a non-profit and non-partisan organisation, established a programme of Sustainable Futures Forums, with sponsorship from National Australia Bank, as a place where key thought leaders and decision makers can come together to discuss issues vital to creating a sustainable future. The forums address issues ranging from local to global in scale, but with a clear focus on issues of direct importance to Australia's future. The forums are a confidential non-partisan platform operating under the Chatham House Rule, thus enabling open and non-attributable exchange of views between key decision makers and influencers. Whilst the forum discussions are completely confidential, each forum is set out with clear aims and objectives. The discussions are focused on delivering tangible outcomes as to how that particular topic should be taken forward. ClimateWorks Australia then provides the mechanism through which actions or recommendations emerging from discussions are progressed. In this way Sustainable Futures Forums translate the best intellectual thinking into real action.

\subsection{Science meets the boardroom}

In May 2009, ClimateWorks Australia held a CEO Forum between Australian business leaders and climate scientists. One of the major conclusions to emerge from that Forum was that Australian businesses, and in particular the boards of those companies, do not have reliable information on climate change and hence do not understand the implications of climate change as a risk or opportunity to their business. Boards tend to derive their views on climate change from the media or personal contacts and often this information is incomplete or just plain wrong. As a result Australian businesses are often not taking climate change into account in their decision making or are making the wrong decisions because they are basing those decisions on inaccurate information. 
It was clear that a mechanism was required whereby Australian businesses are able to speak to a climate expert, and thus have easy access to high quality, balanced, up-to-date information on climate change.

In order to meet the requirement for Australian businesses to have access to the best information on climate change, ClimateWorks Australia initiated a program of Science Meets the Boardroom. In this program ClimateWorks Australia arranges for a world-leading Australian climate scientist to present to and discuss with boards of major Australian-based businesses on the latest science of climate change. As a recent example, Climate Scientists Australia partnered with global professional services firm KPMG to provide briefings in Melbourne and Sydney to director-level clients of the firm.

In this way it is hoped to create dialogue and trust between scientists and business leaders so that business decisions are based on the best science.

\section{CONCLUSIONS}

In this paper we point out that the strength of the scientific consensus in support of a human influence on the climate system is not reflected in public perceptions, where there has been a recent marked decrease in the level of public acceptance in climate change. The paper makes the case that the scientific community, individually and collectively, have an increased role to play in communicating the science of climate change to policymakers, the business community, the media and the public, and gives some examples of initiatives underway in Australia to try and bridge the information gap between climate scientists and various stakeholders.

Acknowledgements. We acknowledge the support of our colleagues at the Monash Sustainability Institute, ClimateWorks Australia and Climate Scientists Australia in carrying out the programmes outlined in this paper, and also the support of The Myer Foundation, the Cranlana Programme, the National Australia Bank and the Diversicon Environmental Founda- tion. We are also grateful for the advice and guidance of the ClimateWorks Australia Board in developing the programmes.

\section{LITERATURE CITED}

Allison I, Bindoff NL, Bindschadler RA, Cox PM and others (2009) Copenhagen diagnosis, 2009: updating the world on the latest climate science. The University of New South Wales Climate Change Research Centre, Sydney

Boykoff MT (2009) We speak for the trees: media reporting on the environment. Annu Rev Environ Resour 34:431-457

Cash DW, Clark WC, Alcock F, Dickson NM and others (2003) Knowledge systems for sustainable development. Proc Natl Acad Sci USA 100:8086-8091

CRED (2009) The psychology of climate change communication: a guide for scientists, journalists, educators, political aides, and the interested public. Center for Research on Environmental Decisions, New York

> Oreskes N (2004) Science and public policy: What's proof got to do with it? Environ Sci Policy 7:369-383

Oreskes N, Conway EM, Shindell M (2008) From Chicken Little to Dr Pangloss: William Nierenberg, global warming, and the social deconstruction of scientific knowledge. Hist Stud Nat Sci 38:109-152

Parry ML, Canziani OF, Palutikof JP, van der Linden PJ, Hanson CE (2007) IPCC, 2007: climate change 2007: impacts, adaptation and ulnerability. Contribution of Working Group II to the Fourth Assessment Report of the Intergovernmental Panel on Climate Change. Cambridge University Press, Cambridge

Pew (2009) Fewer Americans see solid evidence of global warming. Pew Research Center for People and the Press, Washington, DC

Pielke RA Jr (2010) Creating useful knowledge: the role of climate science policy. Chapter 3 in: Driessen PJ, Leroy P, van Vierssen W (eds) From climate change to social change. International Books, Utrecht, p 51-67

Richardson K, Steffen W, Schellnhuber HJ, Alcamo J and others (2009). Climate change: global risks, challenges and decisions. Synthesis report. University of Copenhagen

Solomon S, Qin D, Manning M, Chen Z, Miller HL (eds) (2007) Climate change 2007: the physical science basis. Contribution of Working Group I to the Fourth Assessment Report of the Intergovernmental Panel on Climate Change. Cambridge University Press, Cambridge

UN (2010) Gateway to the UN system's work on climate change: the Secretary General. www.un.org/wcm/content/ site/climatechange/pages/gateway/secretary-general (accessed 29 April 2010)

Proofs received from author(s): February 15, 2010 